\title{
BMJ Open EUPRON: nurses' practice in interprofessional pharmaceutical care in Europe. A cross-sectional survey in 17 countries
}

Elyne De Baetselier (D) , ${ }^{1}$ Bart Van Rompaey, ${ }^{1}$ Luis M Batalha, ${ }^{2}$ Monica Bergqvist, ${ }^{3}$ Bozena Czarkowska-Paczek, ${ }^{4}$ Alberto De Santis, ${ }^{5}$ Nienke E Dijkstra, ${ }^{6}$ Maria I Fernandes, ${ }^{2}$ Izabela Filov, ${ }^{7}$ Vigdis Abrahamsen Grøndahl, ${ }^{8}$ Jana Heczkova, ${ }^{9}$ Ann Karin Helgesen, ${ }^{8}$ Michael Isfort, ${ }^{10}$ Susan Jordan, ${ }^{11}$ Igor Karnjus, ${ }^{12}$ Sarah Keeley, ${ }^{13}$ Petros Kolovos, ${ }^{14}$ Gero Langer, ${ }^{15}$ Manuel Lillo-Crespo, ${ }^{16}$ Vera Logan, ${ }^{11}$ Alba Malara, ${ }^{5}$ Gabriele Meyer, ${ }^{15}$ Andras Olah, ${ }^{17}$ Hana Padysakova, ${ }^{18}$ Mirko Prosen, ${ }^{19}$ Dorina Pusztai, ${ }^{17}$ Carolien G Sino, ${ }^{6}$ Styliani Tziaferi, ${ }^{14}$ Elena Ziakova, ${ }^{18}$ Tinne Dilles $^{1}$

To cite: De Baetselier E, Van Rompaey B, Batalha LM, et al. EUPRON: nurses' practice in interprofessional pharmaceutical care in Europe. A cross-sectional survey in 17 countries. BMJ Open 2020;10:e036269. doi:10.1136/ bmjopen-2019-036269

- Prepublication history and additional material for this paper are available online. To view these files, please visit the journal online (http://dx.doi. org/10.1136/bmjopen-2019036269).

Received 17 December 2019 Revised 24 April 2020 Accepted 29 April 2020

D) Check for updates

(c) Author(s) (or their employer(s)) 2020. Re-use permitted under CC BY-NC. No commercial re-use. See rights and permissions. Published by BMJ.

For numbered affiliations see end of article.

Correspondence to Elyne De Baetselier; elyne.debaetselier@ uantwerpen.be

\section{ABSTRACT}

Objectives Safe pharmaceutical care $(\mathrm{PC})$ requires an interprofessional team approach, involving physicians, nurses and pharmacists. Nurses' roles however, are not always explicit and clear, complicating interprofessional collaboration. The aim of this study is to describe nurses' practice and interprofessional collaboration in PC, from the viewpoint of nurses, physicians and pharmacists.

Design A cross-sectional survey.

Setting The study was conducted in 17 European countries, each with their own health systems.

Participants Pharmacists, physicians and nurses with an active role in PC were surveyed.

Main outcome measures Nurses' involvement in $\mathrm{PC}$, experiences of interprofessional collaboration and communication and views on nurses' competences.

Results A total of 4888 nurses, 974 physicians and 857 pharmacists from 17 European countries responded. Providing patient education and information (PEI), monitoring medicines adherence (MMA), monitoring adverse/therapeutic effects (ME) and prescribing medicines were considered integral to nursing practice by $78 \%, 73 \%, 69 \%$ and $15 \%$ of nurses, respectively. Most respondents were convinced that quality of PC would be improved by increasing nurses' involvement in ME (95\%), MMA (95\%), PEI (91\%) and prescribing (53\%). Mean scores for the reported quality of collaboration between nurses and physicians, collaboration between nurses and pharmacists and interprofessional communication were respectively $<7 / 10, \leq 4 / 10,<6 / 10$ for all four aspects of PC.

Conclusions ME, MMA, PEl and prescribing are part of nurses' activities, and most healthcare professionals felt their involvement should be extended. Collaboration between nurses and physicians on PC is limited and between nurses and pharmacists even more.
Strengths and limitations of this study

First pan-European survey of pharmaceutical care by nurses with insight into the current European situation.

- The large sample size with respondents from three professional groups from 17 European countries.

- Key elements of pharmaceutical care might be understood differently in different countries, due to differences in health systems across Europe, and collaborative development of a conceptual model and the questionnaire may not have overcome inconsistencies in interpretation.

- The sample was self-selected with an unknown response rate, which might have led to a distortion of the results due to only the most motivated professionals participating.

- The findings represent perceptions and are not validated against direct observations.

\section{INTRODUCTION}

In 1990 pharmaceutical care (PC) was defined as the process through which a pharmacist cooperates with a patient and other professionals in designing, implementing and monitoring a therapeutic plan that will produce specific therapeutic outcomes for the patient. This in turn involves three major functions: (1) identifying potential and actual drug-related problems, (2) resolving actual drug-related problems and (3) preventing potential drug-related problems. ${ }^{1}$ In other words, the responsibilities of the PC practitioner are to ensure that all of the medications being taken by the patient are appropriate, effective and safe, and can 
be taken as intended. ${ }^{2}$ It is broadly recognised that there is a need for interprofessional collaboration in PC. ${ }^{3} 4$ Ensing et al corroborated this in their systematic review identifying components of pharmacist interventions that can improve clinical outcomes during care transitions. They concluded that collaborating with other healthcare professionals is crucial to increase the effectiveness of pharmacist interventions. ${ }^{5}$

Nurses are healthcare professionals with significant responsibilities in PC. Dilles et al indicated that nurses regularly engage in pharmaceutical practice, such as providing information, monitoring treatment adherence and recognising adverse drug reactions. ${ }^{6}$ Furthermore, many nurses are continuously in the immediate presence of patients, and therefore well-positioned to deliver PC. ${ }^{7-9}$ However, nurses experience a large number of barriers to safe PC related to medicines monitoring and interprofessional collaboration..$^{6-10}$ Moreover, nurses' roles are not always explicit, distinct and clear to other professionals complicating interprofessional collaboration. ${ }^{6}$

PC requires an interprofessional team approach, involving physicians, nurses and pharmacists. ${ }^{11}$ If nurses are able to raise concerns with physicians and pharmacists, this will help to reduce medication errors. Therefore, interprofessional interactions and open communication are essential for safe PC. ${ }^{11} 12$

An international comparative study in 39 countries, of which 35 were European, indicated a large variation in nurses' roles. Clinical activities traditionally reserved for the medical profession were investigated. It was apparent that task shifting, where nurses, mostly with advanced training, take up advanced roles, such as prescribing medicines, was already implemented in 23 of 35 European countries, to maximise workforce capacity. ${ }^{13} \mathrm{PC}$ activities of nurses, such as patient education, support, adherence monitoring and monitoring patients for potential adverse effects of medicines can be part of nursing practice throughout Europe. Evidence, however, is scarce. Also, in nurse education, a clear description of specific learning outcomes on PC appears to be absent in most European countries. Curricula covering PC vary considerably. ${ }^{513}$ Maier and Aiken state that developing minimum educational and practice standards may facilitate the comparability and recognition of advanced nursing roles across borders and in increasingly connected labour markets. ${ }^{13}$

To our knowledge, there is no research available describing nurses' roles in clinical practice in delivering PC from an interprofessional viewpoint throughout Europe. The aim of this study is to describe nurses' practice and experiences on interprofessional collaboration with nurses in PC, from the viewpoint of nurses, physicians and pharmacists, in different European countries. This study is abbreviated to EUPRON, an acronym for Europe, PC, roles of nurses.

\section{METHODS}

\section{Study design}

In a quantitative, cross-sectional survey in 17 different European countries, nurses, physicians and pharmacists were invited to complete an online structured questionnaire on nurses' practice in selected components of interprofessional PC.

\section{Participants and setting}

Seventeen European countries participated in the study: Belgium, Czech Republic, England, Germany, Greece, Hungary, Italy, The Netherlands, Norway, Poland, Portugal, the Republic of North Macedonia, Slovakia, Slovenia, Spain, Sweden and Wales. Although England and Wales are both part of the UK, and not independent countries, they are mentioned separately because of their different healthcare systems.

Not all European countries participated because inclusion in the project depended on the intrinsic motivation of researchers to join and collaborate in the project, since no funding resources were available at the start. In every country, local nurse researchers were contacted through international nurse associations. All nurse researchers collaborated in the project consortium by national recruitment of volunteer respondents and local data collection. Convenience sampling was used to select nurses, physicians and pharmacists, with an active role in PC for patients in a range of healthcare settings, such as hospitals, community care organisations, residential care settings and mental healthcare organisations. 'Active' was defined as currently working in clinical practice with patients. ${ }^{1415}$ The term physician referred to all medical doctors, including surgeons, irrespective of specialty. Level 5-8 nurses of the European Qualification Framework $^{16}$ (vocational, associate, bachelor, master or $\mathrm{PhD}$ nurses) were eligible, whereas professionals without registered nursing status or in training, and students were excluded.

\section{Survey development}

Based on literature, a conceptual model about nurses' practice in interprofessional PC was developed (online supplementary figure 1). This conceptual model was validated (face validity) by the project consortium of researchers to ensure the fit with local context. Afterwards, based on the model, an English language questionnaire was developed by the consortium of international experts and evaluated and adjusted until consensus was reached (online supplementary material). Following questions on demographics, employment and education, four aspects of PC were addressed: monitoring adverse/ therapeutic effects of medicines (ME), monitoring medicines adherence (MMA), prescribing and providing patient education and information about medicines (PEI). The perceived quality of collaboration between nurses and physicians and between nurses and pharmacists, the perceived quality of nurses' competences and the perceived quality of interprofessional communication 
on the different aspects of $\mathrm{PC}$ were rated with a score of $0-10$ ( $0=$ low quality, $10=$ high quality). The four domains addressed, are part of $\mathrm{PC}$, yet, other responsibilities and tasks could be defined within the concept of PC. ${ }^{12}$ The main content of the questionnaire was the same for nurses, physicians and pharmacists. However, while nurses were questioned about their own practice, physicians and pharmacists were questioned about nurses' practice. The questionnaire was translated into all languages of the participating countries by voluntary and sworn translators. The nurse researchers were asked to check the translation in their own language, and the completion time. Finally, the instrument was piloted with the group of international researchers as to its applicability and comparability in different health system contexts.

\section{Patient and public involvement}

The study participants included pharmacists, physicians and nurses. Since the study focused on healthcare providers, patients and the public were not involved in this study.

\section{Data collection}

We aimed to reach a representative sample of nurses, physicians and pharmacists in each country. Between December 2017 and June 2018, institutions and organisations were asked to distribute the questionnaire and send reminders. Each partner looked for the optimum distribution strategy, depending on local possibilities (existing organisations and networks). A weblink to the questionnaire was sent by email to key stakeholders, professional associations, healthcare facilities and private professional networks. Sampling efforts focused on nurses, pharmacists and physicians. Nursing faculties as well as interprofessional colleagues (Faculty of Medicine and Faculty of Pharmacy) initiated sampling. All contacts were additionally asked to forward the link to colleagues, eligible to participate. The weblink was placed on university websites, webpages of professional associations and on social media. Each country received regular updates about the number of participants.

\section{Data analysis}

Data were analysed using IBM SPSS Statistics V.24.0. A two-sided level of significance of 0.05 was used. Discontinuous data were described using frequency distributions; continuous data were described using a mean value and an SD. Normality of the distribution was tested with the absolute values of the skewness and kurtosis because of the large sample size. ${ }^{17}$ All data were normally distributed. Differences in opinion by nurses, physicians and pharmacists were explored. To evaluate the statistical significance of the differences between the three professional groups, $\chi^{2}$ test for dichotomous variables, one-way analysis of variance (Bonferroni post hoc test) for scale variables and Kruskal-Wallis for ordinal variables were used. Representativity of the sample size per country was shown by a ratio, calculated as: the number of respondents in each country divided by the approximate number of inhabitants in that country multiplied by $100000 .^{18}$ The number of inhabitants per country was chosen to represent the country size, since approximate numbers of nurses, physicians and pharmacists were not available for all countries.

\section{Ethical considerations}

All respondents received information on the purpose, design and execution of the study. Before the digital questionnaire could be started, all respondents had to indicate they had read the study information and consented to participate. Data were collected anonymously to ensure privacy. ${ }^{19}$

\section{RESULTS}

\section{Research population}

A total of 6719 respondents participated, of whom $73 \%$ were nurses, $14 \%$ physicians and $13 \%$ pharmacists. Across the 17 countries, the number of respondents per 100000 inhabitants varied from 0.1 to 36.4 . Mean age was 42 years and $78 \%$ of the population was female. The majority of the respondents worked in a hospital $(61 \%)$ and worked together with one or more nurses and with one or more physicians. Collaboration with one or more pharmacists was reported by $90 \%$ of the pharmacists but only $39 \%$ of the nurses and $42 \%$ of the physicians. More than half of the respondents reported that interprofessional PC was encouraged by their employer's policies. Forty per cent of the nurses had a level 6 post (European Qualification Framework) and 48\% had attended specific extra educational activities focusing on PC after obtaining their nursing qualification. More detailed population characteristics are presented in table 1 .

\section{Monitoring adverse/therapeutic effects of medicines}

Almost $70 \%$ of the nurse respondents had been involved in $\mathrm{ME}$ in the last month, with a higher prevalence of $\mathrm{ME}$ as the level of education decreased (table 2). Across Europe, the proportion of respondents considering ME as part of nurses' roles, varied from $72 \%$ to $98 \%$ (online supplementary figure 2). More healthcare workers in non-ambulatory settings and professionals already collaborating with other professions were convinced of this (respectively, $90 \%$ vs $82 \%, \mathrm{p}<0.001$, online supplementary table 1 , and $88 \%$ vs $55 \%, \mathrm{p}<0.001$, online supplementary table 2). Pharmacists were significantly less likely to recognise ME as part of nurses' roles $(\mathrm{p}<0.001$, table 3$)$.

Almost all respondents (95\%) were convinced of the positive impact of nurses' involvement in $\mathrm{ME}$ on the quality of PC (86\%-98\% across Europe) (online supplementary figure 3). Two-thirds of respondents believed that the involvement of nurses in ME should be extended (table 3).

\section{Monitoring medicines adherence}

MMA was reported as part of nursing practice in the last month by $73 \%$ of nurses. In nurses with lower levels of 
Table 1 Population characteristics $(n=6719)$

\begin{tabular}{|c|c|c|c|c|}
\hline & $\begin{array}{l}\text { All respondents } \\
(\mathrm{n}=6719)\end{array}$ & $\begin{array}{l}\text { Nurses } \\
(n=4888)\end{array}$ & $\begin{array}{l}\text { Physicians } \\
(\mathrm{n}=974)\end{array}$ & $\begin{array}{l}\text { Pharmacists } \\
(\mathrm{n}=857)\end{array}$ \\
\hline Demographical data & n (\%) & $\%$ & $\%$ & $\%$ \\
\hline \multicolumn{5}{|l|}{$\begin{array}{l}\text { Country (respondents/100000 } \\
\text { inhabitants }{ }^{\star}, n \text { ) }\end{array}$} \\
\hline Slovenia (36.4) & $753(11.2)$ & 11.5 & 16.7 & 3 \\
\hline Slovakia (16.6) & $902(13.4)$ & 11 & 11.6 & 29.2 \\
\hline Norway (9.0) & $479(7.1)$ & 6.2 & 6.8 & 12.6 \\
\hline Belgium (8.7) & $992(14.8)$ & 11.8 & 23.3 & 22.1 \\
\hline Czech Republic (8.2) & $868(12.9)$ & 15.1 & 8.4 & 5.5 \\
\hline Wales (6.5) & $202(3.0)$ & 2.9 & 1.1 & 5.6 \\
\hline North Macedonia (6.5) & $134(2.0)$ & 1.7 & 3 & 2.6 \\
\hline Hungary (3.8) & $376(5.6)$ & 6.3 & 5.5 & 1.6 \\
\hline Sweden (2.5) & $256(3.8)$ & 3 & 3.2 & 9 \\
\hline Greece (2.4) & $256(3.8)$ & 4.6 & 2.6 & 0.6 \\
\hline Portugal $(1,3)$ & $130(1.9)$ & 2.3 & 1.4 & 0.7 \\
\hline The Netherlands $(0.8)$ & $134(1.8)$ & 2.2 & 1.1 & 0.2 \\
\hline Germany (0.7) & $584(8.7)$ & 11.3 & 0.3 & 3.2 \\
\hline Italy $(0.6)$ & $341(5.1)$ & 4.7 & 10.8 & 0.5 \\
\hline UK (0.5) & $336(5.0)$ & 5 & 2.2 & 8.5 \\
\hline Poland (0.4) & $167(2.5)$ & 2.7 & 3 & 0.6 \\
\hline England (0.2) & $34(2.0)$ & 2 & 1 & 2.9 \\
\hline Spain $(0.1)$ & $25(0.4)$ & 0.5 & 0.1 & 0.2 \\
\hline Gender (female) & $5242(78.2)$ & 83.3 & 53.2 & 77.6 \\
\hline Age (years), mean (min-max) & $42.0(21-77)$ & $41.8(21-75)$ & $45.1(24-75)$ & $39.5(23-77)$ \\
\hline Job characteristics & $\%$ & $\%$ & $\%$ & $\%$ \\
\hline \multicolumn{5}{|l|}{ Area of CP } \\
\hline Hospital & 61.1 & 66.5 & 67.6 & 30.1 \\
\hline Community or primary care & 18.9 & 16.5 & 19.2 & 44.2 \\
\hline Residential care & 7.3 & 9.5 & 5.8 & 1.4 \\
\hline Educational setting & 0.1 & 0.4 & 0.3 & 0 \\
\hline Other & 12.5 & 7.1 & 7.1 & 23.6 \\
\hline $\begin{array}{l}\text { Work experience in healthcare } \\
\text { (years), mean (SD) }\end{array}$ & $18.0(12.0)$ & 11.8 & 12.8 & 11.5 \\
\hline \multicolumn{5}{|l|}{$\begin{array}{l}\text { Main patient population to take } \\
\text { care for }\end{array}$} \\
\hline Children (0-17 years) & 7.3 & 7.2 & 7.7 & \multirow{4}{*}{$\begin{array}{l}\text { Pharmacists not } \\
\text { questioned }\end{array}$} \\
\hline Adults (18-64 years) & 25.7 & 25.7 & 25.7 & \\
\hline Older persons ( $\geq 65$ years) & 18.7 & 19.7 & 13.5 & \\
\hline More than one age group & 48.3 & 47.4 & 53 & \\
\hline \multicolumn{5}{|l|}{ Domains/rolest } \\
\hline $\mathrm{CP} /$ direct patient care & 100 & 100 & 100 & 100 \\
\hline Research & 37.2 & 38.8 & 39 & 28.9 \\
\hline Management & 61.4 & 68.5 & 38.2 & 52.4 \\
\hline Education & 52.9 & 58.4 & 44.2 & 40.2 \\
\hline $\begin{array}{l}\text { Working in CP (hours/week), } \\
\text { mean (SD) }\end{array}$ & 12.4 & 11.6 & 13.7 & 12.2 \\
\hline
\end{tabular}


Table 1 Continued

\begin{tabular}{llll}
$\begin{array}{l}\text { All respondents } \\
(n=6719)\end{array}$ & $\begin{array}{l}\text { Nurses } \\
(n=4888)\end{array}$ & $\begin{array}{l}\text { Physicians } \\
(n=974)\end{array}$ & $\begin{array}{l}\text { Pharmacists } \\
(n=857)\end{array}$ \\
\hline
\end{tabular}

\begin{tabular}{lllll}
\hline $\begin{array}{l}\text { Number of nurse co-workers in } \\
\text { daily CP }\end{array}$ & & & \\
None & 7.7 & 4.5 & 5.3 & 33.3 \\
$<5$ & 44.9 & 47.3 & 39.3 & 36.4 \\
$5-10$ & 26.1 & 27.5 & 26.9 & 15.4 \\
$>10$ & 21.3 & 20.8 & 28.4 & 15
\end{tabular}

Number of medical co-workers in daily $\mathrm{CP}$

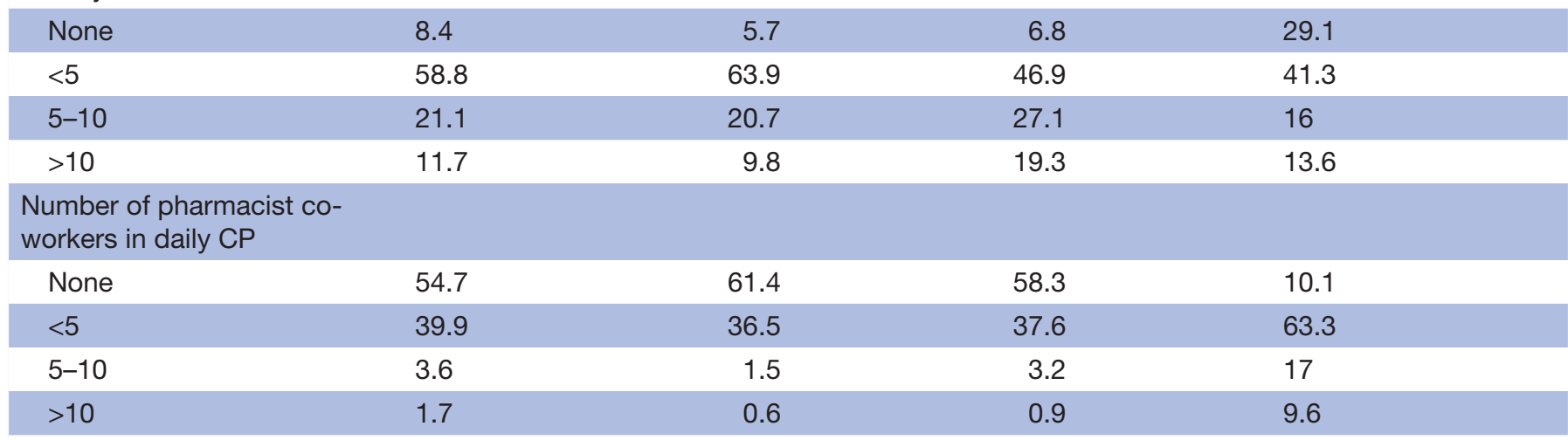

Availability of physician to

discuss patients'

MM rated as good

$\begin{array}{llr}\text { (Strongly) agree } & \text { Only nurses } & 84.4 \\ \text { (Strongly) disagree } & \text { questioned } & 13.8 \\ \text { Do not know } & & 1.8\end{array}$

Availability of pharmacists to

discuss patients'

MM rated as good

\begin{tabular}{|c|c|c|c|c|}
\hline (Strongly) agree & \multirow{3}{*}{$\begin{array}{l}\text { Only nurses } \\
\text { questioned }\end{array}$} & 59.5 & & \\
\hline (Strongly) disagree & & 24.3 & & \\
\hline Do not know & & 16.2 & & \\
\hline Education & $\%$ & $\%$ & $\%$ & $\%$ \\
\hline \multicolumn{5}{|c|}{ Highest educational level (EQF) } \\
\hline 5 & \multirow{4}{*}{$\begin{array}{l}\text { Only nurses } \\
\text { questioned }\end{array}$} & 33.4 & & \\
\hline 6 & & 40.4 & & \\
\hline 7 & & 22.8 & & \\
\hline 8 & & 3.3 & & \\
\hline
\end{tabular}

Time spend on non-mandatory extra education

\begin{tabular}{|c|c|c|c|c|}
\hline$>2$ days/year & 77 & 74.1 & 89 & 80.1 \\
\hline 1-2 days/year & 15.7 & 17.7 & 7 & 14.2 \\
\hline$<1$ day/year & 4.6 & 5.1 & 2.3 & 4.6 \\
\hline $\begin{array}{l}\text { Specific extra educational } \\
\text { activities focusing } \\
\text { on PC or optimisation since } \\
\text { obtaining } \\
\text { nursing qualification }\end{array}$ & $\begin{array}{l}\text { Only nurses } \\
\text { questioned }\end{array}$ & 47.7 & & \\
\hline
\end{tabular}


Table 1 Continued

$\begin{array}{llll}\begin{array}{l}\text { All respondents } \\ (n=6719)\end{array} & \begin{array}{l}\text { Nurses } \\ (n=4888)\end{array} & \begin{array}{l}\text { Physicians } \\ (n=974)\end{array} & \begin{array}{l}\text { Pharmacists } \\ (n=857)\end{array}\end{array}$

\begin{tabular}{|c|c|c|c|c|}
\hline \multicolumn{5}{|l|}{$\begin{array}{l}\text { Interprofessional MM is } \\
\text { encouraged by } \\
\text { employers' policies }\end{array}$} \\
\hline (Strongly) agree & 58.8 & 56.2 & 58 & 76 \\
\hline (Strongly) disagree & 25.3 & 27.8 & 21.9 & 13.5 \\
\hline Do not know & 15.9 & 16 & 20 & 10.6 \\
\hline
\end{tabular}

${ }^{*}$ The number of persons having their usual residence in a country on 1 January 2018. Number of inhabitants was chosen to represent the country size, since the approximate number of nurses, physicians and pharmacists was not available for all countries. ${ }^{15}$ †More than one answer possible.

CP, clinical practice; EQF, European Qualifications Framework ${ }^{14}$; MM, medicines management; PC, pharmaceutical care.

education, MMA was significantly more a part of their activities than in nurses with higher educational levels (table 2). Pharmacists, healthcare workers in ambulatory settings and professionals who did not collaborate with nurses were less likely to recognise MMA as part of nurses' roles (table 3 , online supplementary table 1 and online supplementary table 2). In Hungary, $31 \%$ of the respondents considered MMA as part of nurses' role, while across the rest of Europe this varied from $82 \%$ to $98 \%$ (online supplementary figure 2). Almost all respondents (95\%) were convinced of the positive impact of nurses' involvement in MMA on the quality of PC $(89 \%-100 \%$ across Europe) (online supplementary figure 3). According to $65 \%$ of respondents, the involvement of nurses in MMA should be extended. However, nurses were less convinced $(63 \%)$ of the need to extend their involvement than physicians $(70 \%)$ and pharmacists $(71 \%)(\mathrm{p}<0.001)$ (table 3$)$.

\section{Prescribing medicines}

Nurse prescribing was the aspect of PC least likely to be reported as part of nursing practice in the last month (15\%; with a range across Europe from $7 \%$ to $30 \%$ ) (figure 1, table 2). No difference in educational level existed. Almost one-third of the nurses stated prescribing was a part of their role, which was significantly more than physicians' $(\mathrm{p}<0.001)$ and pharmacists' $(\mathrm{p}<0.001)$ (table 3). Professionals working in primary or community care and professionals collaborating with nurses were more likely to evaluate prescribing as part of nurses' roles (respectively $32 \%$ vs $27 \%, \mathrm{p}=0.008$, online supplementary table 1 and $28 \%$ vs $13 \%, \mathrm{p}<0.001$, online supplementary table 2). Across Europe, the proportion of respondents acknowledging prescribing as part of nurses' roles differed: from $11 \%$ in Germany to $52 \%$ in Wales and $81 \%$ in The Republic of North Macedonia $(p<0.001)$ (online supplementary figure 2). However, at the time of data collection only England, The Netherlands, Poland, Sweden and Wales had legislation in place for non-medical prescribing, usually restricted to specialised nurses and/ or certain medicines. More nurses $(60 \%)$ were convinced of the positive impact of nurse involvement in prescribing medicines on the quality of PC than physicians (39\%) or pharmacists $(29 \%) \quad(\mathrm{p}<0.001)$. Across Europe, between $35 \%$ and $75 \%$ of respondents felt that nurse prescribing had a positive impact on care quality (online supplementary figure 3). More than half of all nurses thought their involvement in prescribing should be extended, which was significantly higher than physicians $(29 \%, \mathrm{p}<0.001)$ and pharmacists $(23 \%, \mathrm{p}<0.001)$ (table 3$)$.

Providing patient education and information about medicines More than three-quarters of the nurses reported PEI as part of their practice in the last month, with more PEI activities as the level of education decreased (table 2). Across Europe, the proportion of respondents that acknowledged PEI as part of nurses' roles, varied from $55 \%$ to $93 \%$ (online supplementary figure 2). Pharmacists and professionals who did not collaborate with nurses were significantly less likely to consider PEI as part of nurses' roles $(\mathrm{p}<0.001)$. Almost all respondents $(91 \%)$ were convinced of the positive impact of nurse involvement in PEI on the quality of PC (table 3). This ranged from $81 \%$ to $100 \%$ across Europe (online supplementary figure 3). Two-thirds of the respondents believed that the involvement of nurses in PEI should be extended (table 3).

\section{Quality of interprofessional collaboration, interprofessional communication and nurses' competences in PC}

The mean reported perceived quality of collaboration between nurses and physicians on ME, MMA, prescribing and PEI varied from 5.9/10 to 6.6/10. Between nurses and pharmacists scores were lower $(3.6 / 10-4 / 10)$. Professionals who already collaborated interprofessionally, rated the quality of collaboration more highly than noncollaborating professionals (online supplementary table 2 ). These 'collaborating' professionals were also more likely to consider ME, MMA, prescribing and PEI as part of nurses' roles and to acknowledge the positive impact of nurse involvement in PC. Detailed comparisons can be found in online supplementary table 2 . Nurses rated their own competence on a self-rating scale more highly $(4.8 / 10-7.1 / 10)$ than did physicians (4.0/10-6.3/10) and pharmacists $(3.7 / 10-5.2 / 10)$ (figure 2$)$. The scores 
Table 2 Nurses' self-reported prevalence of different aspects of pharmaceutical care (PC) and reported actions or opinions concerning PC, split up for the different educational levels

\begin{tabular}{|c|c|c|c|c|c|c|}
\hline Monitoring adverse/therapeutic effects & $\begin{array}{l}\% \text { of all } \\
\text { nurses }\end{array}$ & $\begin{array}{l}\% \text { of level } 5 \\
\text { nurses } \\
(n=1570)\end{array}$ & $\begin{array}{l}\% \text { of level } 6 \\
\text { nurses } \\
(n=1897)\end{array}$ & $\begin{array}{l}\% \text { of level } 7 \\
\text { nurses } \\
(n=1072)\end{array}$ & $\begin{array}{l}\% \text { of level } \\
8 \text { nurses } \\
(n=156)\end{array}$ & $P$ value \\
\hline Part of activities last month & 69.1 & 74.2 & 70.8 & 61.2 & 52.6 & $<0.001$ \\
\hline \multicolumn{7}{|l|}{ Actions after observing an adverse effect ${ }^{\star}$} \\
\hline Discussed with a physician & 90.1 & 90.1 & 89.3 & 91.7 & 88.9 & 0.194 \\
\hline Discussed with a pharmacist & 7.6 & 6.8 & 7.5 & 7.9 & 14.4 & 0.009 \\
\hline Discussed with a nurse & 43.6 & 44.7 & 44.7 & 40.5 & 41.2 & 0.108 \\
\hline Discussed with the patient & 39.1 & 40.2 & 39.3 & 37 & 39.2 & 0.438 \\
\hline Reported in the patient file & 61.2 & 66.6 & 58.9 & 58.2 & 56.2 & $<0.001$ \\
\hline Intervened on own initiative & 28.4 & 29.9 & 24.5 & 32.8 & 30.1 & $<0.001$ \\
\hline Nothing & 0.1 & 0.2 & 0.1 & 0.1 & 0 & 0.821 \\
\hline Never observed an adverse effect & 4.1 & 3.5 & 4.9 & 3.5 & 3.3 & 0.108 \\
\hline Monitoring medicines adherence & $\%$ & & & & & \\
\hline Part of activities last month & 73 & 82.7 & 70.6 & 66.3 & 53 & $<0.001$ \\
\hline \multicolumn{7}{|l|}{ Actions after observing non-adherence ${ }^{*}$} \\
\hline Discussed with a physician & 83.5 & 86 & 81.6 & 83.3 & 84.4 & 0.016 \\
\hline Discussed with a pharmacist & 5 & 3.7 & 5.2 & 5.4 & 10.9 & 0.001 \\
\hline Discussed with a nurse & 43.7 & 44.5 & 44.8 & 41 & 41.5 & 0.232 \\
\hline Discussed with the patient & 58.5 & 61.8 & 56 & 58.6 & 55.8 & 0.014 \\
\hline Reported in patient file & 60.4 & 68 & 56.4 & 57.8 & 53.1 & $<0.001$ \\
\hline Intervened on own initiative & 16.8 & 19.2 & 13.7 & 18.2 & 19.7 & $<0.001$ \\
\hline Nothing & 0.4 & 0.3 & 0.4 & 0.6 & 0 & 0.502 \\
\hline Never observed non-adherence & 6.7 & 5.3 & 8 & 7.2 & 5.4 & 0.026 \\
\hline Prescribing medicines & $\%$ & & & & & \\
\hline Part of activities last month & 14.9 & 13.7 & 15.3 & 15.6 & 18.2 & 0.364 \\
\hline \multicolumn{7}{|l|}{$\begin{array}{l}\text { Actions after observing inappropriate } \\
\text { prescribing by any professional }^{\star}\end{array}$} \\
\hline Discussed with a physician & 78.2 & 81.5 & 73.4 & 81.6 & 78.9 & $<0.001$ \\
\hline Discussed with a pharmacist & 8.2 & 6.5 & 8.8 & 8.7 & 14.3 & 0.007 \\
\hline Discussed with a nurse & 35.8 & 38.2 & 34.5 & 34.3 & 39.1 & 0.137 \\
\hline Discussed with the patient & 16.9 & 18.6 & 15.1 & 17.3 & 18 & 0.091 \\
\hline Reported in the patient file & 26.3 & 32 & 23.3 & 23.9 & 25.6 & $<0.001$ \\
\hline Intervened on own initiative & 13.8 & 17.2 & 10.8 & 14.2 & 15.8 & $<0.001$ \\
\hline Nothing & 0.3 & 0.2 & 0.3 & 0.2 & 0.8 & 0.586 \\
\hline Never noticed inappropriate prescribing & 17.9 & 15.9 & 22.2 & 14.3 & 9.8 & $<0.001$ \\
\hline $\begin{array}{l}\text { Providing patient education and } \\
\text { information about medicines (PEI) }\end{array}$ & $\%$ & & & & & \\
\hline Part of activities last month & 78.1 & 81.2 & 77.4 & 76.1 & 71.1 & 0.004 \\
\hline \multicolumn{7}{|l|}{ Nurse opinions concerning PEI ${ }^{\star}$} \\
\hline $\begin{array}{l}\text { Pharmacists, physicians, nurses were well } \\
\text { aware of PEI by each team member }\end{array}$ & 20.1 & 16.1 & 21.6 & 23.6 & 17.3 & 0.021 \\
\hline Feeling qualified to PEI & 36.6 & 34.8 & 37.5 & 36.4 & 46.2 & 0.379 \\
\hline Enough information of physician to PEI & 39 & 21.9 & 20.7 & 14.1 & 11.5 & 0.008 \\
\hline $\begin{array}{l}\text { Other professions would have given better } \\
\text { PEI }\end{array}$ & 20 & 16.4 & 12.4 & 12.3 & 9.6 & 0.116 \\
\hline
\end{tabular}

*More than one answer possible; $p$ values were calculated with $\chi^{2}$ test for the difference between educational levels, $p<0.05$ are in bold. 
Table 3 Nurse involvement in four aspects of pharmaceutical care from the viewpoint of nurses, physicians and pharmacists

\begin{tabular}{|c|c|c|c|c|}
\hline & $\begin{array}{l}\text { Nurses' } \\
\text { viewpoint } \\
\text { (n=4888) }\end{array}$ & $\begin{array}{l}\text { Physicians' } \\
\text { viewpoint } \\
(\mathrm{n}=974)\end{array}$ & $\begin{array}{l}\text { Pharmacists' } \\
\text { viewpoint } \\
(\mathrm{n}=857)\end{array}$ & $\begin{array}{l}\text { Overall } \\
\text { viewpoint } \\
(n=6719)\end{array}$ \\
\hline Monitoring adverse/therapeutic effects (ME)* & $\%$ & $\%$ & $\%$ & $\%$ \\
\hline Part of nurses' role & 93 & 73 & 62.9 & 81.2 \\
\hline Convinced of positive impact of nurse involvement on PC & 95.9 & 92.6 & 88 & 94.5 \\
\hline \multicolumn{5}{|l|}{ Involvement of nurses in ME should: } \\
\hline Remain the same & 29.9 & 28.2 & 24.8 & 29 \\
\hline Be restricted & 1.9 & 2.3 & 6 & 2.4 \\
\hline Monitoring medicines adherence (MMA)* & $\%$ & $\%$ & $\%$ & $\%$ \\
\hline Part of nurses' role & 94.7 & 84 & 75.8 & 85.2 \\
\hline Remain the same & 35.2 & 28.8 & 24.8 & 33 \\
\hline Be restricted & 1.4 & 1.6 & 4 & 1.8 \\
\hline Prescribing medicines* & $\%$ & $\%$ & $\%$ & $\%$ \\
\hline Part of nurses' role & 30.3 & 22.1 & 21.3 & 23.1 \\
\hline Convinced of positive impact of nurse involvement on PC & 60.1 & 38.9 & 29.3 & 53.3 \\
\hline \multicolumn{5}{|l|}{ Involvement of nurses in prescribing medicines should be: } \\
\hline Extended & 54.6 & 28.9 & 22.8 & 46.9 \\
\hline Remain the same & 32.2 & 49.4 & 37.9 & 35.6 \\
\hline Restricted & 13.2 & 21.7 & 39.3 & 17.4 \\
\hline Remain the same & 28.9 & 30.9 & 29.8 & 29.3 \\
\hline Restricted & 2.6 & 5.3 & 11.3 & 4 \\
\hline
\end{tabular}

*Viewpoint of nurses, physicians, pharmacists was significantly different $(p<0.001)$ for all variables except for 'involvement of nurses in ME should be extended/remain the same/be restricted' $(p=0.775)$. P value was calculated with $\chi^{2}$ test for 'part of nurses' role' and 'convinced of positive impact' and Kruskal-Wallis test for 'nurse involvement should be extended/remain the same/be restricted'.

for the reported quality of interprofessional communication varied from $5.0 / 10$ to $5.7 / 10$. Here, pharmacists gave a significantly lower score $(4.3 / 10-4.5 / 10)$ than nurses (5.1-5.9/10) and physicians $(4.9 / 10-5.7 / 10)$ (figure 3). More detailed scores across Europe are presented in online supplementary figures $4-7$.

\section{DISCUSSION}

The EUPRON data clearly describe nurses' routine clinical practice in PC. Although some variation is apparent, the differences between the 17 countries in practice, competence, collaboration and communication in PC are not as large as expected.

We investigated four different PC activities. Most nurses were actively involved in ME, PEI and MMA the last month, particularly the nurses with lower educational attainment. Nearly all nurses, physicians and pharmacists believed nurse involvement positively impacted on the quality of PC. Also, most nurses, physicians and pharmacists were convinced ME, PEI and MMA are part of nurses' role. Moreover, an extension of nurses' roles in ME, PEI, MMA was proposed by two-thirds of respondents. However, scores were suboptimal in all four different aspects of PC for the quality of: nurses' competences, collaboration of nurses with physicians or pharmacists and interprofessional communication.

The lowest ratings for collaboration related to nursepharmacist working. This may reflect the observation that pharmacists were the least frequently mentioned co-workers in clinical practice, and this lack of familiarity 


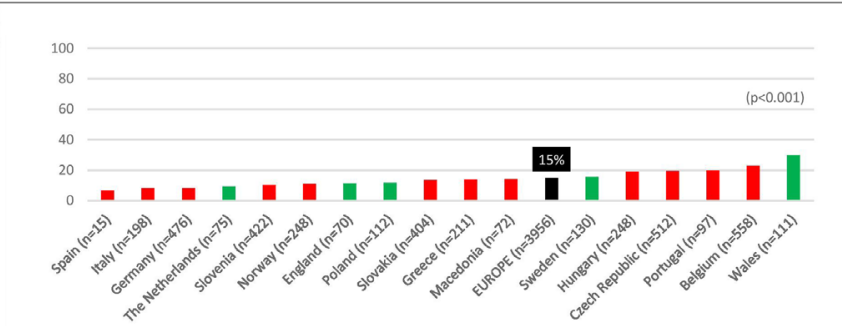

Green bars = prescribing medicines is legally allowed for some nurses (specialised) and for some medicines.

Red bars = prescribing medicines is not legally allowed

Black bar = Europe

Figure 1 Percentages of nurses stating that prescribing medicines was part of their activities last month, by country and across Europe as a whole. $\mathrm{P}$ values was calculated with $\chi^{2}$ test.

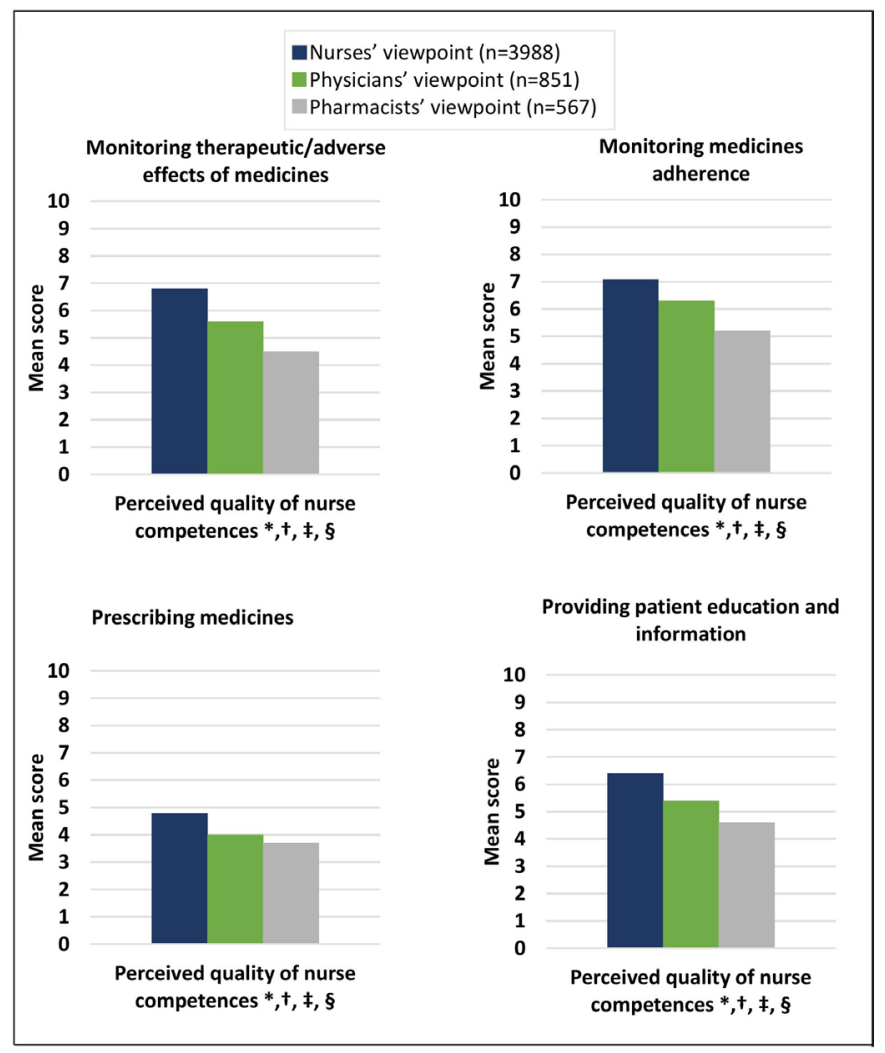

Figure 2 Mean scores (on 10) for the reported selfperceived quality of nurse competences in pharmaceutical care (split up for four aspects), from the viewpoint of nurses, physicians and pharmacists. ${ }^{*} \mathrm{P}<0.05$ for the difference in mean quality score between nurses/physicians/pharmacists (overall comparison, one-way analysis of variance); $\dagger p<0.05$ for the difference in mean quality score between nurses and physicians (pair-wise comparison, Bonferroni post hoc test); $\neq \mathrm{p}<0.05$ for the difference in mean quality score between nurses and pharmacists (pair-wise comparison, Bonferroni post hoc test); $\$ p<0.05$ for the difference in mean quality score between physicians and pharmacists (pair-wise comparison, Bonferroni post hoc test).
- Nurses' perceived quality of collaboration / communication score (mean, $n=3991$ ) - Physicians' perceived quality of collaboration / communication score (mean, $n=842$ )

- Pharmacists' perceived quality of collaboration / communication score (mean, $n=566$ )

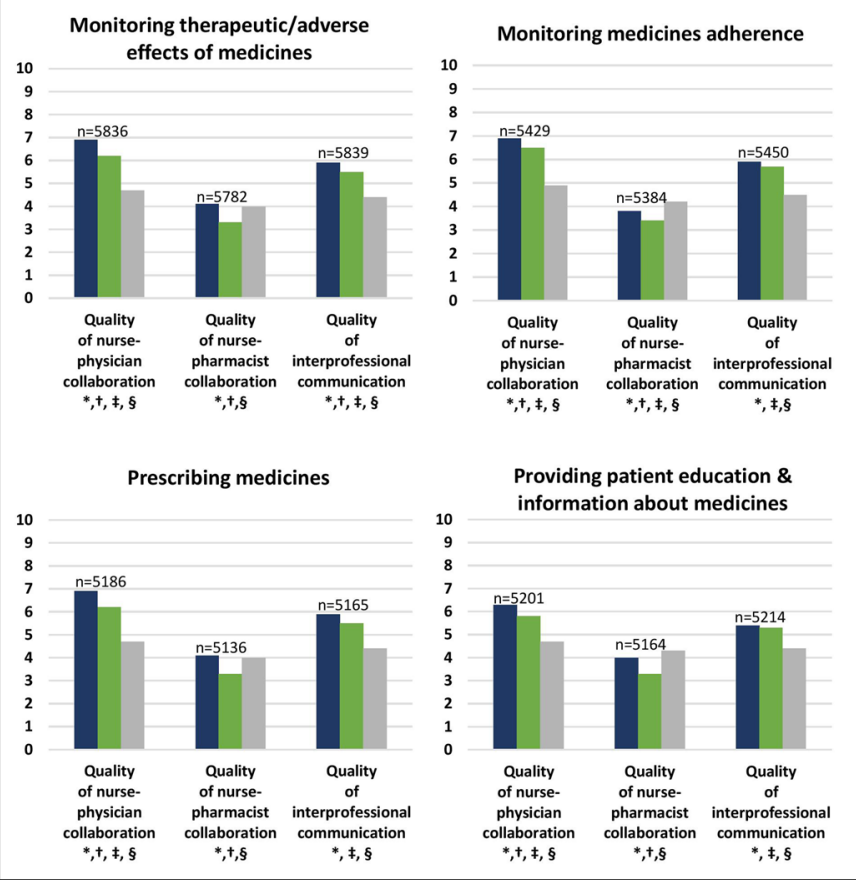

Figure 3 Score (on 10) for the reported self-perceived quality of collaboration between nurses and physicians, collaboration between nurses and pharmacists and interprofessional communication in pharmaceutical care (split up for four aspects), from the viewpoint of nurses, physicians and pharmacists. ${ }^{*} \mathrm{P}<0.05$ for the difference in mean quality score between nurses/physicians/pharmacists (overall comparison, one-way analysis of variance); $\uparrow \mathrm{p}<0.05$ for the difference in mean quality score between nurses and physicians (pair-wise comparison, Bonferroni post hoc test); $\neq \mathrm{p}<0.05$ for the difference in mean quality score between nurses and pharmacists (pair-wise comparison, Bonferroni post hoc test); $\$ p<0.05$ for the difference in mean quality score between physicians and pharmacists (pair-wise comparison, Bonferroni post hoc test).

might have influenced pharmacists' perceptions of nurses' practice. After all, it is more difficult to understand another professionals' role, when not working directly with them. The literature on nurse-pharmacist collaborations is contradictory. A study in Pakistan found poor collaboration between nurses and pharmacists: $24 \%$ of the nurse study population $(n=220)$ never or rarely interacted with a pharmacist. ${ }^{20} \mathrm{~A}$ Chinese study found positive attitudes towards nurse-pharmacist collaboration, even though there was still room for improvement and American research showed nurse-pharmacist collaboration was efficient and cost-effective, which improved patient safety. ${ }^{2122}$ In Europe, there is little recent research on nurse-pharmacist collaboration. A UK study reported limited contact between community pharmacists and nurse prescribers, in contrast to the reported frequency of contact with other healthcare professionals. Yet, there 
are positive views on pharmacist-nurse team-working. ${ }^{23} \mathrm{~A}$ recent review by Celio et al in European as well as nonEuropean countries concluded pharmacist-nurse medication adherence-enhancing interventions are rare and often in the nascent phase. ${ }^{24}$

Our findings on nurse prescribing were surprising: prevalence was much higher than expected, based on the legislation in the participating countries. Only The Netherlands, Poland, Sweden and the UK legally permitted nurse prescribing at the time of data collection. ${ }^{13}$ However, in all other countries some nurses indicated having prescribed the last month. In addition, one-quarter of the nurses, physicians and pharmacists believed prescribing was part of nurses' role, with up to $81 \%$ in The Republic of North Macedonia, where nurse prescribing is not legally allowed. After discussing these results within the research consortium, the experts concluded the term 'prescribing' might have been interpreted by respondents as selecting and applying medicinal products for wound care. Another possibility is that prescribing was not legally allowed, yet performed by nurses in an informal, unofficial way. Maier and Aiken described how prescriptive authority by nurses can vary from no authority to a limited or a broad range of activities officially authorised. ${ }^{13}$ In some countries, nurses are allowed to prescribe a wide range of medicines within certain specialties. Levels of independence range from fully independent to various forms of physician oversight, depending on types of medicines and country-specific governance structures. The study of Maier and Aiken in 39 countries, of which 35 European, indicated task shifting from physicians to nurses, for example, prescribing by nurses, has become common in many countries. ${ }^{13}$

This study showed lower educated nurses were more likely to monitor patients for adverse/therapeutic effects and medication adherence and provided more patient education/information. Our results partly correspond to a previous study of Dilles $e t$ al on nurses' practice in PC and association with educational level (diploma vs bachelor nurse). There, more diploma nurses observed nonadherence, yet more bachelor nurses observed adverse drug reactions. No differences for providing patient education/information were shown. ${ }^{6}$

The results in this study showed nurses are willing to extend their involvement in all areas of PC. This suggests nurses believe PC is the responsibility of teams in which they are included. While nurses favoured an expansion of their involvement in prescribing, this was not supported by pharmacists. On the contrary, $39 \%$ were in favour of restricting nurses' involvement.

Although most nurses were performing several activities of $\mathrm{PC}$, and consequently taking responsibility in parts of PC, our findings show nurses' competences in PC were reported as rather low. The lack of clarity in nurses' roles in PC can contribute to nurses not receiving sufficient training in different aspects of PC. A clear definition of roles however, is a fundamental prerequisite for effective education and collaboration among nurses, physicians and pharmacists, for delivering safe care to patients and meeting patients' needs. ${ }^{24}$ Effective team communication and better training in interprofessional collaboration is needed to tackle adverse patient events. ${ }^{25-31}$ Therefore, nurse education curricula as well as the curricula of all other disciplines need to address these weaknesses. ${ }^{32}$

\section{Strengths and limitations}

This study is unique because of its large sample size and diversity, consisting of respondents of three professional groups from 7 European countries. To our knowledge, this is the first pan-European survey of PC by nurses. Despite the limited number of participants at the national level, the overall data provided interesting first insight in the current European situation.

This internet survey had limitations. The inclusion or exclusion of countries and respondents was determined by whether they agreed or declined to participate in the study. This self-selected sample with an unknown response rate might have led to a distortion of the results due to only the most motivated professionals participating. Also, the sample favoured more educated computerliterate professionals, due to use of internet recruitment. Another limitation that needs to be taken into account when interpreting the results is the differences in health systems across Europe. Despite the conceptual model and international collaboration in the questionnaire development, key elements of PC might be understood differently, as discussed for the term 'prescribing'. Finally, we acknowledge that our findings represent perceptions and are not validated against direct observations or correlated with any outcomes.

\section{Implications and recommendations for practice and research}

Because of the descriptive nature of this survey, few associations were explored. Differences exist, for example, in area of clinical practice or educational attainment. Further research, zooming in on possible associations, is needed to highlight these differences and identify areas of greatest need.

The EUPRON data demonstrated that throughout Europe, nurses' contribution to interprofessional PC is not transparent and differs between countries, in both law and practice. The lack of transparency and recognition, combined with international variation, in both nursing practice and education, can hinder collaboration on different levels: quality of interprofessional communication and collaboration in daily clinical practice; transnational collaboration in research, education and innovation across Europe and labour mobility of nursing students and nurses. Further research is needed to explore whether the level of education and practice variation is associated with variation in patient outcomes, particularly in terms of medication errors, the prevalence of adverse effects and hospitalisation for adverse effects.

In EUPRON, we decided to use a quantitative study design to investigate the current clinical practice of nurses in PC. Insights in the strengths and weaknesses of nurses' 
practice today, and in the opportunities and threats for the future cannot be extracted out of the EUPRON data. An in-depth qualitative study in all partner countries, interviewing nurses, physicians and pharmacists, would create a strengths, weaknesses, opportunities and threats (SWOT) analysis on nurses' roles in interprofessional PC in the different countries, and in Europe as a whole. This would allow learning about good practice, and the prerequisites for patient safety, which can then form the basis for development of a model for nurses' roles in interprofessional PC. Subsequently, this model could be a framework for interprofessional collaboration in clinical practice, education, transnational collaboration in research in Europe and labour mobility of nurses and nursing students.

\section{CONCLUSION}

Monitoring adverse/therapeutic effects of medicines, monitoring medicines adherence, prescribing medicines and providing patient education and information about medicines are part of the activities of nurses in clinical practice. Healthcare professionals felt that nurse involvement should be extended. The quality of collaboration between nurses and physicians on pharmaceutical care is limited and between nurses and pharmacists even more so.

\author{
Author affiliations \\ ${ }^{1}$ Nursing and Midwifery, Faculty of Medicine and Health Sciences, University of \\ Antwerp, Wilrijk, Belgium \\ ${ }^{2}$ Higher School of Nursing of Coimbra Health Sciences Research Unit Nursing, \\ Coimbra, Portugal \\ ${ }^{3}$ Department of Neurobiology Care Sciences and Society, Karolinska Institutet, \\ Huddinge, Sweden \\ ${ }^{4}$ Department of Clinical Nursing, Medical University of Warsaw, Warsaw, Poland \\ ${ }^{5}$ ANASTE-Humanitas Foundation, Rome, Italy \\ ${ }^{6}$ Research Group Care for the Chronically III, HU University of Applied Sciences \\ Utrecht, Utrecht, The Netherlands \\ ${ }^{7}$ Saint Kliment Ohridski University Bitola, Bitola, Bitola, The former Yugoslav \\ Republic of Macedonia \\ ${ }^{8}$ Faculty of Health and Welfare, Østfold University College, Halden, Norway \\ ${ }^{9}$ Institute of Nursing Theory and Practice, Charles University First Faculty of \\ Medicine, Praha, Czech Republic \\ ${ }^{10}$ Deutsches Institut für angewandte Pflegeforschung e V, Köln, Germany \\ ${ }^{11}$ Nursing, Swansea University, Swansea, UK \\ ${ }^{12}$ Department of Nursing, University of Primorska College of Health Care, Izola, \\ Slovenia \\ ${ }^{13}$ Department of Nursing and Clinical Science, Bournemouth University, Dorset, UK \\ ${ }^{14}$ Department of Nursing, Laboratory of Integrated Health Care, University of \\ Peloponesse, Sparti, Greece \\ ${ }^{15}$ Medical Faculty, Institute of Health and Nursing Sciences, Martin-Luther- \\ Universitat Halle-Wittenberg, Halle (Saale), Germany \\ ${ }^{16}$ Department of Nursing, Universitat d'Alacant, Alacant, Spain \\ ${ }^{17}$ Institute of Nursing Sciences, Basic Health Sciences and Health Visiting, University \\ of Pecs Faculty of Health Sciences, Pecs, Hungary \\ ${ }^{18}$ Faculty of Nursing and Professional Health Studies, Slovak Medical University in \\ Bratislava, Bratislava, Slovakia \\ ${ }^{19}$ Faculty of Health Sciences, Department of Nursing, University of Primorska \\ College of Health Care, Izola, Slovenia
}

Twitter Elyne De Baetselier @EBaetselier, Bart Van Rompaey @BartRompaey, Nienke E Dijkstra @DijkstraNE, Manuel Lillo-Crespo @manuellilloc, Mirko Prosen @ MirkoProsen and Tinne Dilles @TinneDilles
Acknowledgements The authors would like to thank Sabina Ličen (University of Primorska), Nia Griffin (Swansea University), Paulo Alexandre Carvalho Ferreira (Nursing School of Coimbra), Soraia Alves Rodrigues (Hospital Centre Baixo Vouga), Catariana Abrantes da Silva (Hospital Centre Baixo Vouga), Francesco Talarico (Pugliese-Ciaccio Hospital), Toke Vanwesemael (University of Antwerp), Filip Haegdorens (University of Antwerp), Kelly Sabbe (University of Antwerp) for their valuable contribution in collecting data and reviewing the manuscript.

Contributors EDB, BVR, NED, CS, TD contributed to the design of the study. EDB, BVR, LMB, MB, BC-P, ADS, NED, MIF, IF, VAG, JH, AKH, MI, SJ, IK, SK, PK, GL, ML-C, VL, AM, GM, AO, HP, MP, DP, CS, ST, EZ, TD contributed to the data collection. EDB conducted the data analysis. All authors contributed to the interpretation of the data, and the preparation and refinement of the final manuscript.

Funding This work was supported by the Erasmus+Programme of the European Union (grant number 2018-1-BE02-KA203-046861) and MDMJ accountants, an accountancy service in Belgium that financially supported the Belgian authors, without any conflicts of interest.

Competing interests None declared.

Patient and public involvement Patients and/or the public were not involved in the design, conduct, reporting or dissemination plans of this research.

Patient consent for publication Not required.

Ethics approval The Ethics Committee for Social Sciences and Humanities of the University of Antwerp approved the study design. Depending on local regulations, in some countries additional approval from local organisations: Health Research Authority approval and Bournemouth University approval (England), Ethical Committee of School of Human Movement and Quality of Life of University of Peloponnese (Greece), Health Science Council-Scientific and Research Ethics Committee (Hungary), Bioethics Commission at the Medical University of Warsaw (Poland), Ethics Committee of the Nursing Sciences Research Unit of the Nursing School of Coimbra (Portugal), Integrated Research Application System ethical approval and Research \& Development departments (Wales).

Provenance and peer review Not commissioned; externally peer reviewed.

Data availability statement Data are available on reasonable request. All data relevant to the study are included in the article or uploaded as supplementary information.

Open access This is an open access article distributed in accordance with the Creative Commons Attribution Non Commercial (CC BY-NC 4.0) license, which permits others to distribute, remix, adapt, build upon this work non-commercially, and license their derivative works on different terms, provided the original work is properly cited, appropriate credit is given, any changes made indicated, and the use is non-commercial. See: http://creativecommons.org/licenses/by-nc/4.0/.

\section{ORCID iD}

Elyne De Baetselier http://orcid.org/0000-0002-1586-7825

\section{REFERENCES}

1 Hepler CD, Strand LM. Opportunities and responsibilities in pharmaceutical care. Am J Hosp Pharm 1990;47:533-43.

2 Cipolle RJ, Strand LM, Morley PC. Pharmaceutical care practice: the patient-centered approach to medication management. 3 edn. McGraw-Hill Education, 2012.

3 Kijlstra N, Ridge K, Walser S. Pharmaceutical care: where do we stand - where should we go? Key concepts in pharmaceutical care, quality assessment of pharmaceutical care in Europe, sources of information: survey report. Strasbourg: European Directorate for the Quality of Medicines \& HealthCare (EDQM), 2009.

4 Keitel S. Pharmaceutical care - policies and practices for a safer, more responsible and cost-effective health system. Strasbourg: European Directorate for the Quality of Medicines \& HealthCare (EDQM), 2012.

5 Ensing HT, Stuijt CCM, van den Bemt BJF, et al. Identifying the optimal role for pharmacists in care transitions: a systematic review. J Manag Care Spec Pharm 2015;21:614-36.

6 Dilles T, Vander Stichele R, Van Rompaey B, et al. Nurses' practices in pharmacotherapy and their association with educational level. $J$ Adv Nurs 2010;66:1072-9.

7 Jordan S, Hardy B, Coleman M. Medication management: an exploratory study into the role of community mental health nurses. $J$ Adv Nurs 1999;29:1068-81. 
8 Lata PF, Mainhardt M, Johnson CA. Impact of nurse case managerpharmacist collaboration on adverse-drug-event reporting. Am J Health Syst Pharm 2004;61:483-7.

9 Bergqvist M, Ulfvarson J, Andersen Karlsson E, et al. A nurse-led intervention for identification of drug-related problems. Eur J Clin Pharmacol 2008;64:451-6.

10 Jordan S, Hughes D. Community teamwork is key to monitoring the side-effects of medication. Nurs Times 2000;96:39-40.

11 Choo J, Hutchinson A, Bucknall T. Nurses' role in medication safety. J Nurs Manag 2010;18:853-61.

12 Thoma JE, Waite MA. Experiences of nurse case managers within a central discharge planning role of collaboration between physicians, patients and other healthcare professionals: a sociocultural qualitative study. J Clin Nurs 2018;27:1198-208.

13 Maier CB, Aiken LH. Task shifting from physicians to nurses in primary care in 39 countries: a cross-country comparative study. Eur J Public Health 2016;26:927-34.

14 Etikan I, Musa S, Alkassim R. Comparison of convenience sampling and purposive sampling. AJTAS 2016;5:1-4.

15 Polit DF, Beck CT. Nursing research: generating and assessing evidence for nursing practice. 10 edn. Philadelphia: Wolters Kluwer Health, 2017.

16 European Commission. The European qualification framework for lifelong learning (EQF). Luxembourg: Office for Official Publications of the European Communities, 2008.

$17 \mathrm{Kim} \mathrm{H}$-Y. Statistical notes for clinical researchers: assessing normal distribution (2) using skewness and kurtosis. Restor Dent Endod 2013;38:52-4.

18 Eurostat. Population on 1 January 2018, 2018. Available: https://ec. europa.eu/eurostat/tgm/refreshTableAction.do?tab=table\&plugin=1\& pcode $=$ tps00001\&language $=$ en

19 World Medical Association. World Medical association declaration of Helsinki: ethical principles for medical research involving human subjects. JAMA 2013;310:2191-4.

20 Khan AN, Khan MU, Shoaib MH, et al. Practice nurses and pharmacists: a perspective on the expectation and experience of nurses for future collaboration. Oman Med $J$ 2014;29:271-5.
21 Wang S-P, Wang J, Huang Q-H, et al. Pharmacy and nursing students' attitudes toward nurse-pharmacist collaboration at a Chinese university. BMC Med Educ 2018;18:179.

22 Feldman LS, Costa LL, Feroli ER, et al. Nurse-pharmacist collaboration on medication reconciliation prevents potential harm. $J$ Hosp Med 2012;7:396-401.

23 While A, Shah R, Nathan A. Interdisciplinary working between community pharmacists and community nurses: the views of community pharmacists. J Interprof Care 2005;19:164-70.

24 Celio J, Ninane F, Bugnon O, et al. Pharmacist-nurse collaborations in medication adherence-enhancing interventions: a review. Patient Educ Couns 2018;101:1175-92.

25 Wilson AJ, Palmer L, Levett-Jones T, et al. Interprofessional collaborative practice for medication safety: nursing, pharmacy, and medical graduates' experiences and perspectives. J Interprof Care 2016;30:649-54.

26 Azhar S, Hassali MA, Mohamed Ibrahim MI, et al. A survey evaluating nurses' perception and expectations towards the role of pharmacist in Pakistan's healthcare system. $J$ Adv Nurs 2012;68:199-205.

27 Reeves S, Pelone F, Harrison R, et al. Interprofessional collaboration to improve professional practice and healthcare outcomes. Cochrane Database Syst Rev 2017;6:Cd000072.

28 Dinius J, Gaupp R, Becker S, et al. Patient safety in hospitals: what we do and what we need-focus groups with stakeholders of hospitals in southern Germany. J Patient Saf 2017. doi:10.1097/ PTS.0000000000000452. [Epub ahead of print: 15 Dec 2017]

29 Jordan S, Logan PA, Panes G, et al. Adverse drug reactions, power, harm reduction, regulation and the ADRe profiles. Pharmacy 2018;6:102

30 Müller $\mathrm{M}$, Jürgens $\mathrm{J}$, Redaèlli $\mathrm{M}$, et al. Impact of the communication and patient hand-off tool SBAR on patient safety: a systematic review. BMJ Open 2018;8:e022202.

31 Pirmohamed $M$, James $S$, Meakin S, et al. Adverse drug reactions as cause of admission to hospital: prospective analysis of 18820 patients. BMJ 2004;329:15-19.

32 Ebert L, Hoffman K, Levett-Jones T, et al. "They have no idea of what we do or what we know": Australian graduates' perceptions of working in a health care team. Nurse Educ Pract 2014:14:544-50. 